Br. F. Anaesth. (1988), 60, 733-735

\title{
GRAND MAL SEIZURE AFTER EXTRADURAL MORPHINE ANALGESIA
}

\author{
A. BORGEAT, J. BIOLLAZ, B. DEPIERRAZ AND R. NEFF
}

Major advances have been made in our understanding of the sites and mechanisms of action of opioid agents $[1,2]$. Recent reports indicate that effective and prolonged pain relief can be obtained in man by the injection of small doses of morphine or pethidine into either the subarachnoid [3] or the extradural space [4]. As a result, extradural morphine analgesia is being used increasingly by clinicians $[5,6]$, especially in obstetrics and gynaecology [7]. Side effects attributed to extradural morphine are common, possibly dose-related and include nausea and vomiting, pruritus, urinary retention and (more rarely) early and late respiratory depression [8]. Seizure, a theoretical complication of intraspinal administration of opioids [9], has been reported only once before and it happened after what was probably a high pressure intrathecal injection in a patient with known metastatic breast cancer [10]. We report the case of a patient who developed a generalized tonicclonic seizure $6 \mathrm{~h}$ after the administration of morphine $3 \mathrm{mg}$ into the extradural space.

\section{CASE REPORT}

A 30-yr-old woman (gravida 4, para 3), weighing $75 \mathrm{~kg}$, was referred to our department for an elective Caesarean section as an ultrasound scan had shown the presence of twins in the breech position at 37 weeks gestation. The actual pregnancy was free of incident; there was no hypertension, oedema or proteinuria.

At the age of $19 \mathrm{yr}$ the patient had suffered her first grand mal seizure. Investigations did not reveal any brain lesion and she had no family

A. Borgeat, M.D., B. DepierRaz, M.D., R. NEFF, M.D. (Department of Anesthesiology and Reanimation); J. BIOLLAZ, M.D. (Division of Clinical Pharmacology); Centre Hospitalier Universitaire Vaudois, CH 1011, Lausanne CHUV, Switzerland. Accepted for Publication: February 24, 1987.

Correspondence to A.B.

\section{SUMMARY}

Following an elective Caesarean section under extradural anaesthesia, a 30-yr-old known epileptic woman (gravida 4, para 3) developed a tonic-clonic seizure, $6 \mathrm{~h}$ after the administration of morphine $3 \mathrm{mg}$ into the extradural space. Possible aetiological factors are discussed.

history of epilepsy. From that time, she was treated with phenobarbitone $175 \mathrm{mg}$ daily, and suffered one or two grand mal fits each year up to the age of $26 \mathrm{yr}$. She had had an uneventful pregnancy terminated by forceps delivery under extradural bupivacaine analgesia at age $29 \mathrm{yr}$.

It was decided to utilize extradural anaesthesia. Ringer's solution $1500 \mathrm{ml}$ was infused and the patient was placed in the left lateral decubitus position. Using the "loss of resistance" technique, the extradural space was entered at L2-3 with an 18-gauge Tuohy needle and the catheter was advanced $5 \mathrm{~cm}$ cranially without difficulty. An aspiration test revealed neither blood nor CSF and $1 \%$ lignocaine $2 \mathrm{ml}$ was injected through the catheter. As neither motor nor sensory deficit occurred, a second aspiration test (also negative) was carried out $5 \mathrm{~min}$ later and $2 \%$ carbonated lignocaine $20 \mathrm{ml}$ (Astra) with freshly added adrenaline $0.1 \mathrm{mg}$ was injected at a rate of $5 \mathrm{ml} \mathrm{min}^{-1}$. The resulting sensory block extended to $\mathrm{T} 5$ on both sides. Two male infants (2440 and $2540 \mathrm{~g}$ ) were delivered with Apgar scores of $8 / 9 / 10$ and $7 / 9 / 10$, respectively. A bilateral tubal ligation was performed and a continuous infusion of oxytocin (10 u. in $5 \%$ glucose $500 \mathrm{ml}$ over $12 \mathrm{~h}$ ) was started.

At the end of the procedure and following a negative aspiration test, $3 \mathrm{mg}$ of preservative-free morphine (Vifor, Geneva) was administered in $10 \mathrm{ml}$ of physiological saline via the extradural 
catheter. The immediate postoperative period was uneventful. Analgesia was satisfactory, the rate of ventilation was within the normal range and normovolaemia (as assessed by diuresis and central venous pressure) was maintained. Four hours after the administration of the extradural morphine, a slight pruritus of the face and the neck was noted, but this was not severe enough to necessitate medical treatment. Two hours later, without alterations in vital signs or warning symptoms, the patient suffered a generalized tonic-clonic seizure with loss of consciousness. The plasma concentration of phenobarbitone $\left(16.2 \mu \mathrm{g} \mathrm{ml}^{-1}\right)$ was within the therapeutic range and close to that measured at 25 weeks gestation $\left(17.1 \mu \mathrm{g} \mathrm{m}^{-1}\right)$. An EEG performed 3 days later was characterized by a diffuse and non-specific abnormal tracing.

\section{DISCUSSION}

Grand mal seizures can be precipitated by a number of factors, including certain drugs and pregnancy [11]. The increase in seizure frequency reported in pregnancy is thought to be the result of a pregnancy-associated alteration in the kinetics of antiepileptic agents, causing a decrease in the plasma concentration. When dosage was adjusted to maintain plasma concentrations in the therapeutic range, no increase in seizure frequency was observed [12]. In this patient, the plasma concentration of phenobarbitone was in the therapeutic range. Furthermore, with the same therapeutic regimen, the patient had suffered no seizure during the previous $4 \mathrm{yr}$, despite another pregnancy terminated by forceps delivery under extradural bupivacaine analgesia $1 \mathrm{yr}$ before the event reported here.

Experimentally, the intracerebroventricular or intrathecal administration of morphine possesses convulsant properties $[13,14]$, in contrast to i.v. morphine, which has been used to suppress convulsions in eclampsia [15]. Bromage and colleagues [16] have shown cervical and intracranial spread of morphine injected into the lumbar extradural space in man and have observed a time-lag of approximately $6 \mathrm{~h}$ for the drug to reach the brain stem and the fourth ventricle.

The poor lipid-solubility of morphine, with its consequential restriction to CSF, implies a high concentration of free drug. Thus, the CNS irritating properties of morphine may have been enough to initiate a grand mal seizure in a patient whose trigger threshold was already low. The 6-h delay between the administration of the morphine and the onset of seizure in our patient is consistent with the known kinetics of morphine in the CSF $[16,17]$. Factors known to induce seizures, such as pain, hyper- or hypoventilation or hypervolaemia, were all absent and cannot be considered contributory factors in this patient. Moreover, the penetration of morphine into the CNS was heralded by the development of pruritus, known to be one of the earliest side-effects of extradural morphine.

Although lignocaine, with its known central nervous system toxicity [18], either alone or by interacting with morphine [19], might have played a role in this patient, the absence of other CNS symptoms of lignocaine toxicity, such as dizziness, auditory and visual disturbances, coupled to the rather long delay between the administration of the lignocaine and convulsions $(8 \mathrm{~h})$ [20] argue against such a role.

In conclusion, although extradural morphine administration greatly improves the comfort of the patient after Caesarean section, its administration to epileptic patients might be questioned and should at least be monitored carefully.

\section{REFERENCES}

1. Calvillo O, Henry JL, Neuman RS. Effects of morphine and naloxone on dorsal horn neurones in the cat. Canadian Journal of Physiology and Pharmacology 1974; 52 : 12071211.

2. Pert CB, Kuhar MJ, Snyder SH. Opiate receptor: autoradiographic localization in rat brain. Proceedings of the National Academy of Sciences of the USA 1976;73: 3729-3733.

3. Wang JK. Pain relief by intrathecally applied serotonin or morphine. Annales de l'Anesthésiòlogie Française 1978; 19: 371-376.

4. Behar M, Magora F, Olshwang D, Davidson JT. Epidural morphine in the treatment of pain. Lancet 1979; 1 : 527-529.

5. Kalso E. Effects of intrathecal morphine, injected with bupivacaine, on pain after orthopaedic surgery. British Journal of Anaesthesia 1983; 55: 415-422.

6. Paterson GMC, McQuay HJ, Bullingham RES, Moore RA. Intradural morphine and diamorphine dose-response studies. Anaesthesia 1984; 39: 113-117.

7. Binsted RJ. Epidural morphine after Caesarean section. Anaesthesia and Intensive Care 1983; 11 : 130-134.

8. Bromage PR. State of the art: extradural and intrathecal narcotics. American Society of Anesthesiology 1981; 136: $1-4$.

9. Cousins MJ, Mather LE. Intrathecal and epidural administration of opioids. Anesihesiology 1984; 61: 276310. 
10. Landow $\mathrm{L}$. An apparent seizure following inadvertent intrathecal morphine. Anesthesiology 1985; 62: 545-546.

11. Weber M, Schweitzer M, Mur JN. Epilepsie, médicaments antiépileptiques et grossesse. Archives Françaises de Pédiatrie $1977 ; 34$ : 374-383.

12. Dam $M$, Philbert A. Antiepileptic drug therapy in pregnancy. In: Krauer B, Krauer F, Hytten E, del Pozo E, eds. Drugs and Pregnancy: Maternal Drug Handling-Fetal Drug Exposure. London: Academic Press, $1984 ; 115$.

13. Deneau GA, Nakai $K$. The toxicity of normeperidine in the monkey as influenced by its rate of absorption. Minutes of the 23rd Meeting of Committee on Drug Addiction and Narcotics. Washington DC NAS-NRC, 1961.

14. Stockard J, Bickford R. The neurophysiology of anesthesia. In: Gordon E, ed. Basis and Practice of Neuroanesthesia. Amsterdam: Excerpta Medica, 1975; 3.
15. Bowman WC, Rand MJ. Textbook of Pharmacology, 2nd Edn. Oxford: Blackwell Scientific Publications, 1980; 20-42.

16. Bromage PR, Camporesi EM, Durant PAC, Hielsen $\mathrm{CH}$. Rostral spread of epidural morphine. Anesthesiology 1982; 56: $431-436$.

17. Jacobson L. Intrathecal and extradural narcotics. Advances in Pain Research and Therapy 1984; 7: 199-236.

18. Mather LE, Cousins MJ. Local anesthetics and their current clinical use. Drugs $1979 ; 18$ : 185-205.

19. Goodson JM, Moore PA. Life-threatening reactions after pedodontic sedation: an assessment of narcotic, local anesthetic, and antiemetic drug interaction. Fournal of the American Dental Association 1983; 107 : 239-241.

20. Mazze RI, Dunbar RW. Plasma lidocaine concentrations after caudal, lumbar, epidural, axillary block, and intravenous regional anesthesia. Anesthesiology 1966; 27: 574-579. 